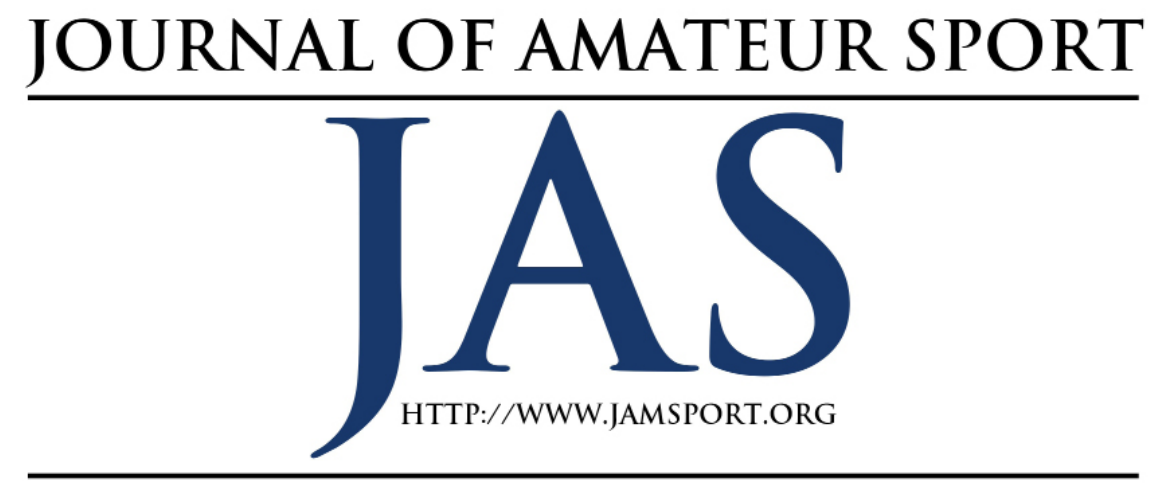

\title{
Navagating Role Ambiguity \& Conflict: Exploring the Role of the Referee Within the Olympic Sporting Structure
}

\author{
Brittany L. Jacobs ${ }^{1}$ \\ Claire C. Zvosec ${ }^{2}$ \\ ${ }^{1}$ Nichols College \\ ${ }^{2}$ Louisiana State University \\ ${ }^{3}$ University of Northern Colorado
}

Brent D. Oja ${ }^{3}$

\begin{abstract}
This phenomenological study seeks to better understand the role of the referee in the Olympic sporting structure and to deconstruct the apparent dichotomies that exist within this role. Eleven rugby sevens referees each completed a pre-Olympics and post-Olympics interview for a total of twenty-two interviews. From the data, four sources of role ambiguity or conflict emerged: (1) remaining unnoticed vs. media exposure; (2) the team vs. individualistic nature of officiating; (3) being a judge vs. being an athlete, and (4) amateurism vs. professionalism. This study discusses how these dichotomies highlight the major sources of role ambiguity and role conflict for rugby sevens officials within the larger Olympic context. Implications regarding increased role clarity, reduced role strain, and referee management are discussed.
\end{abstract}

\section{Introduction}

Whe use of an official within a sporting competition has become synonymous with the formalization of the sporting endeavor, differentiating it from recreational play. Within organized sport, referees serve as the arbiters of a match and their "im- pact on the development or outcome of a game can be significant" (Ste-Marie, 2003, p.170). As such, referees play a vital role in the sporting system, yet on a global scale, a shortage of referees exists in many sports and at nearly every level of competition (e.g., Rayner, Webb, \& Webb, 2016; Ridinger, Warner, Tingle, 
\& Kim, 2017; Warner, Tingle, \& Kellett, 2013). As referees discontinue participation, sport organizations are forced to adapt-often resulting in modified game times, obscure match schedules, matches managed by a skeleton crew of officials, or matches covered by underqualified officials (Ridinger, 2015). Much of the extant literature has considered officiating through the lens of attrition, seeking to combat the factors that lead to professional dropout. Performance concerns, time constraints, interpersonal conflicts, lack of recognition, and fear of physical abuses have been cited as sources of stress related to referee attrition (Rainey \& Hardy, 1999). Taylor, Daniel, Leith, and Burke (1990) examined intention to terminate as a result of such stresses.

Because of the aforementioned referee shortage and the number of stressors impacting referee retention, scholars have sought to determine what motivates referees to continue participation. Kellett and Shilbury (2007) found that referees were retained when they were able to reframe abuses, normalizing these behaviors, primarily through social connection with other referees. Additional scholars have suggested that a sense of belonging to a larger community or elimination of administrative issues may motivate officials to continue participation (Kellett \& Shilbury, 2007; Kellett \& Warner, 2011).

Beyond stressors and motivators, the officiating experience has been explored within the context of a match (Berman, 2011); from a gendered perspective (Nordstrom, Warner, \& Barnes, 2016;
Schaeperkoetter, 2017; Tingle, Warner, \& Sartore-Baldwin, 2014); and through the analysis of decision-making, bias, and supporting technologies (Larkin, Berry, \& Lay, 2011; Leveaux, 2010). Despite the growing body of work regarding sport officials, Kellett and Warner (2011) suggested that referees are often considered to be service providers within the context of sport, rather than being understood as participants. Thus, within the larger sporting structure, little is known about a referee's unique on and off-court roles (Kellett \& Warner, 2011).

The lack of exploration of referee roles represents a gap in the research. While many scholars have suggested that referee recruitment and retention are of primary importance for sporting organizations, the role ambiguity and role conflict that referees experience has yet to be considered. In other contexts, scholars have associated role ambiguity and conflict with satisfaction (Eys, Carron, Bray, \& Beauchamp, 2003; Koustelios, Theodorakis, \& Goulimaris, 2004), and burnout, while others have suggested that an understanding of individual role responsibilities can be one of the most important variables in team sport (Carron, 2003). In an industry where referee retention is of utmost importance, a firm understanding of the referee's distinctive role becomes paramount. As such, this study seeks to consider the distinctive role of the referee and the ambiguity and conflict that may exist within the context of rugby sevens at the Olympics. Olympic level officials participate within numerous sporting 
structures. They are all representatives of a particular country's referee society, but also contractors for World Rugby (the international body for the sport). As such, their role expectations are created from numerous role senders and they must operate within myriad organizational structures and countries. To explore any phenomenon the importance of experience with the topic is key-these elite level officials provide such experience.

For the purposes of this study, role will be generally defined as the function assumed or part played by a person in a particular social situation (McGrath, 1984). Referees, regardless of the sport they officiate, share commonalities in their role as an official (Dorsch \& Paskevich, 2007). The referee's on-field role is multi-faceted, with responsibilities that include: managing the events of a match, applying the rules of the game, maintaining a fair competition, and addressing conflict between sporting participants (Dell, Gervis, \& Rhind, 2016). While roles are often constructed based upon one's presumed responsibilities or personal status (Carron, Hausenblas, \& Eys, 2005), little is known about a referee's larger role in the Olympic sporting structure. In fact, as rugby sevens is new to the Olympics, this study will be the first to investigate the role of a rugby sevens referee.

The 2016 Olympics in Rio de Janeiro were the first Olympics to host rugby since 1924. Rugby sevens is a unique version of the game boasting seven players per side and mixing fast scoring with intense physical play. For the 2016 Olympics, the men's and women's rugby sevens events were managed by a total of 28 match officials, including 24 referees and four assistant referees, representing 14 different countries. In sevens, each match utilizes one center referee (referred to as the referee), two assistant referees, and two in-goal judges for a total of five on-field match officials. While the referee is ultimately responsible for all decisions made on the field, the assistant referees and in-goal judges operate in a supporting capacity. The inclusion of rugby sevens in the Olympics for the first time creates a unique opportunity to explore the referee's perceptions of their role as it identifies a group of elite officials through whom the researchers may be able to deconstruct potential sources of role ambiguity or role conflict. Thus, the following research questions are proposed:

1. What is the role of the rugby sevens referee within the Olympic sporting structure?

2. In what ways is role ambiguity and/or role conflict present within the referee's role?

\section{Literature Review}

\section{Role Theory}

Role theory concerns patterns in one's behavior based on the expectations that exist due to positions held (Biddle, 1986). These characteristic behaviors that manifest existing expectations are defined as roles. Role theory posits that there are numerous ways to define a role 
within various contexts (Biddle, 1986). Further, within the field of role theory, several perspectives have surfaced: functional, structural, organizational, symbolic interactionist perspectives, and cognitive role theory. A common thread between all of the major role theory perspectives is that which relates expected behavior based on context or social identity (Biddle, 1986).

When misalignment occurs between expectation and behavior, it can be described as either role ambiguity or role conflict, which can lead to role strain (Eys, Carron, Bray, \& Beauchamp, 2005; Koustelios et al., 2004). In the officiating realm, society and sporting structures often construct the role expectations for the referee-to act and be regarded as a service provider or volunteer (Cuskelly, Hoye, \& Auld, 2006). At times, these role expectations may not align and with misalignment comes stress. As previous scholars of referees have indicated, stressors can increase the risk of referee burnout and ultimately attrition (e.g., Tingle et al., 2014; Warner et al., 2013). Likewise, it has been shown that role ambiguity and role conflict also lead to decreased job satisfaction (Jackson \& Schuler, 1985).

\section{Role Ambiguity}

Role ambiguity is defined as a lack of clarity or information regarding a specific role (Kahn et al., 1964) and there are a plethora of reasons why a referee may lack clarity in their role expectations. Eys, Carron, Beauchamp, and Bray (2005) identified sources of role ambiguity for athletes as factors associated with the coach, the situation, and the athlete himself or herself. Further, this construct has been operationalized by an athlete's uncertainty regarding (a) the scope of their responsibilities, (b) their behaviors associated with role responsibilities, (c) the processes of evaluation related to their role, and (d) the consequences when their role is not carried out (Beauchamp, Bray, Fielding, \& Eys, 2005). As an athlete experiences role ambiguity resultant from these sources, it follows that a referee participating in the same sporting context may experience similar role ambiguity. Role ambiguity has been shown to negatively influence athlete satisfaction and performance effectiveness (Carron \& Hausenblas, 1998) and has also been associated with other psychosocial measures, including anxiety and depression (Beauchamp, Bray, Eys, \& Carron, 2003).

Beyond this, high levels of role ambiguity are associated with lower levels of organizational commitment and correlated with turnover (Van Sell, Brief \& Aldag, 1981). As such, it is worthwhile to explore not only whether ambiguity exists for referees but also whether it may impact attrition since recruitment and retention of sporting officials has become a priority for sporting organizations (e.g., Cuskelly \& Hoye, 2004; Ridinger, Kim, Warner, \& Tingle, 2017; Warner et al., 2013). Further, Jackson and Schuler (1985) suggested that if the focal person-in this case the referee-experiences significant role ambiguity, they may 
“...seek alternative situations that are less discomforting" (p. 41), ultimately leading to dropout or role change. In summary, the detrimental effect of role ambiguity on affective states has been clearly articulated, and it has been shown elsewhere that it may also negatively impact the athlete's adherence to their team or, in a larger sense, their position or self-perceived role. Thus, reducing role ambiguity and addressing role clarity may assist in the retention of referees and thereby be beneficial for those in officiating (Eys, Carron, Beauchamp et al., 2005).

\section{Role Conflict}

Taylor and colleagues (1990) posited that an additional factor must be considered with regard to real and perceived officiating stressors: role conflict. Role conflict has been viewed as the "incongruity of the expectations associated with one or more roles" (Van Sell, Brief, \& Schuler, 1981, p. 44). Such incongruity may result from one of several types of conflict, as outlined by Kahn et al. (1964). One type of role conflict is defined as arising from intra-sender role conflict; here, incompatible expectations exist from a single role sender. An example in the in the world of academia is for a professor to act as both a full-time teacher and researcher as dictated by their superior. This type of role conflict has parallels with role ambiguity. A parent and teacher that issue conflicting expectations exemplifies a second type of role conflict, termed inter-sender role conflict. This type of role conflict exists when there are conflicting expectations from two or more role senders. In this instance the inter-sender role conflict arises from the parent forbidding the use of digital technology, while the teacher requires all homework be submitted online.

A third type of conflict, termed person-role conflict, is expressed as the incompatibility between personal values and role expectations. For example, a person of a particular faith may be unable to meet certain training day expectations, as the expectations for their religious beliefs prevent certain activities on holy days. A fourth conflict, inter-role conflict, occurs when pressures exist from two or more positions that are not in alignment. When this type of conflict exists, the focal person may hold the role of mother and primary bread-winner creating potential for misalignment of these roles. A final role conflict arises from the impact of role overload, which occurs when there are multiple expectations that require accountability for various responsibilities and conditions where there is insufficient time or resources to complete expected tasks (Kahn et al., 1964). Such a role conflict may exist at work when a new employee is inundated with projects, though they have not yet learned how to utilize the programs and softwares required to do so. Role conflict is shown to result in employment related tension and job dissatisfaction for individuals, as well as producing other negative organizational outcomes. These have included: lower organizational commit- 
ment (Baird, 1969), a negative relationship between role conflict and happiness, and a positive relationship between role conflict and fatigue, depression, and irritation (Beehr, Walsh, \& Taber, 1976)

Such findings from the literature suggest that when considering the role of the referee in the sporting structure, it will be important to consider the potential for role conflict and to identify where and when this conflict arises. Understanding such ambiguity and conflict will enhance the possibility of creating role clarity.

\section{Methodology}

In this phenomenological study, we examined role of the referee within the Olympic sporting structure. Phenomenology is the study of a phenomenon through the lived experiences of a participant (Crotty, 1998). Stewart and Mickunas (1990) expressed four philosophical perspectives that foundational to a phenomenological study: (1) a return to traditional tasks of philosophy-a search for wisdom; (2) a philosophy without presuppositions [epoche]-suspending judgements until they can be founded upon participant data; (3) intentionality of consciousness-the relationship between one's reality and consciousness of a phenomenon, and; (4) refusal of subject-object dichotomy-reality can only be perceived from the meaning that an individual associates with their experiences. As such, the researchers began the study with an opened question, "What is the role of the rugby sevens referee within the Olympic sporting structure?"
This question allowed the researchers to be guided by participant data throughout the first round of interviews. In this study the researchers adhered to the cornerstones of hermeneutic phenomenology as they searched for wisdom regarding the referee's role. Hermeneutic phenomenology acknowledges the impossibility of bracketing all external knowledge and allows for the integration of outcomes with pre-existing theory (Caelli, 2000; Dahlberg, Drew, \& Nystrom, 2008). Thus, the researchers utilized participant data, along with their knowledge of role theory, in the development of the second interview guide and research question. The second research question, thus, inquired about the ways in which role ambiguity and conflict may present within the referees' role. To investigate any phenomenon, it is important to go beyond anecdote and identify extant meanings, critiquing these meanings through a holistic approach (Crotty, 1998). The use of two (pre-Olympics and post-Olympics) semi-structured interviews with eleven match officials allowed the researchers to explore the role of the referee within the Olympics sporting structure.

\section{Participants}

At the 2016 Olympic Games in Rio de Janeiro, Brazil, 24 match officials oversaw the rugby sevens competitions, along with four appointed assistant referees. From this sampling of 28 Olympic rugby match officials, 10 center referees and one assistant referee participated in this study. In the game of rugby sevens, the 
center referee may serve in an assistant capacity for some games (in a sideline or endline role), but the assistant referees will not serve as a center referee. The participants included seven women and four men. All officials that participated in this study noted that they had participated in rugby as a player at some point throughout their career, and nearly half had played for their country's national team. The average age of the participants was 32 , with the average age of the men slightly exceeding that of the women, 33 and 31 respectively. The sample included referees representing eight countries in the following continents: North America, Australia, Africa, Europe, South America, and Asia.

\section{Procedure}

Participants were recruited via purposive sampling, which is defined as having been selected based on the characteristics of the population and the objectives of the study (Palinkas et al., 2015). Because there are a limited number of people that could serve as a primary data source to examine this phenomenon, participants in this study were purposefully selected for inclusion (Creswell, 2013). To select these participants, the World Rugby Sevens Referee Manager was contacted in order to access those who had been named as Olympic-level rugby sevens referees. From there, the Referee Manager directly contacted the referees and assistant referees who would be appointed to the Olympics on behalf of the researchers. Those who were willing to participate were asked to contact the primary investigator directly to schedule participation in the study. Eleven match officials (10 referees and one assistant referee) volunteered for participation and completed both interviews. Prior to the first interview, participants completed a consent form. The primary investigators conducted two phone and/or Skype interviews with each participant: three weeks prior to the 2016 Olympics in Rio de Janeiro and within one month after the closing ceremonies to confirm expectations or perceptions. The interviews were audio recorded and ranged in length from 40-75 minutes. Throughout the research process, the researchers also maintained observational notes to ensure that the study could be replicated.

\section{Instrument}

Semi-structured interviews were employed to deconstruct the human experience and to ascribe meaning to those experiences through a phenomenological approach (Merriam, 2009). Semi-structured interviews allow the researchers to compare between participant cases, ensuring that the core questions of the interview remain the same (Gratton \& Jones, 2004). The semi-structured approach also allows the conversation to flow naturally, ensuring that additional insights are not missed due to the rigidity of questioning (Creswell, 2013).

The researchers developed two semi-structured interview guides-one interview guide for the pre-Olympics interviews and one interview guide for 
the post-Olympics interviews. The initial interview guide was created based upon previous research in both refereeing and organizational behavior and was reviewed by all three investigators to ensure face validity. Open ended questions focused on the role of the referee in the sporting context, with a minimal number of demographic questions during the first interview to create context for the referee's described experiences. In phenomenological research, it is suggested that multiple interviews be completed in order to verify information presented in initial interviews, extrapolate additional information, and to provide a setting in which the participant is comfortable and willing to share personal information with the researchers (Glaser \& Strauss, 1967; May, 1991; Polkinghorne, 1989). Thus, two interviews were completed with each participant. The second interview guide was developed after each participant had been interviewed once. Questions in the post-Olympic interview guide were derived directly from themes that emerged from the participants. These methods align well with a hermeneutic phenomenological methodology in that several external perspectives, frameworks, and concepts developed out of the pre-Olympics interview data. From that data, such frameworks (e.g., role conflict and role ambiguity) were utilized to aid in the development of the post-Olympics interview guide.

\section{Data Analysis}

Each interview was audio recorded and transcribed verbatim by the researchers. To protect the identity of participants, each interviewee was given a pseudonym. The data was analyzed using inductive thematic analysis in order to maintain alignment with the phenomenological methodology of the study. Inductive analysis allows the researchers to draw from the shared experiences of the participants.

Using inductive thematic analysis, the researchers followed the following process: (1) become familiar with the data, (2) generate initial codes from the open-ended responses of the participants, (3) assesse the codes to create themes, and (4) generate a thematic map from created themes (Vaismoradi, Turunen, \& Bondas, 2013). To become familiar with the data, the researchers completed verbatim transcriptions of the interviews by hand. This provided the researchers with a cursory overview of the information contained within each interview. Beyond this, the researchers maintained a research journal in order to note key thoughts and ideas throughout both the interview and transcription process. Once the interviews had been transcribed, the data was manually coded. The coding process included the generation of an initial code book which included 36 codes from the first round of interviews. Using the codebook, significant statements and ideas were 
categorized. From these initial codes, the researchers came together to assess patterns and determine salient themes. Ten themes emerged from the first round of interviews and provided a nuanced account of information communicated in the data (Braun \& Clarke, 2006). These initial themes created the foundation for the second interview guide. The aforementioned process was then replicated with the second set of interview data allowing the researchers to explore many aspects of role theory, including the concepts and nuances of role ambiguity and role conflict.

\section{Trustworthiness and Dependability}

Guba and Lincoln (1994) suggested that for qualitative research to be trustworthy it must be: (1) confirmable; (2) dependable; (3) credible; and, (4) transferable. Numerous procedures have been adopted to ensure the viability of study results, including: audio-recorded interviews, verbatim interview transcription, and the maintenance of an in-depth research journal helps to ensure that the data collected and the themes garnered are both as dependable and as confirmable as possible. The use of audio recording and the maintenance of a research journal provide a framework for replication and verification of this study. Additionally, verbatim transcription ensures that the respondents voices are reflected in the outcomes of the study, aligning with the tenants of a phenomenological methodology. Beyond the collection of relevant data through strong research processes, the credibility of this research is also enhanced via peer review, member checking, and clarifying researcher bias. Peer-checking and member-checking ensured the validity of emergent themes, decreasing the potential for researcher bias (Creswell, 2013). Researcher biases are addressed below and researchers made a concerted effort throughout the study to bracket out their pre-existing beliefs regarding officiating by allowing the participant data to drive the outcomes of the study.

\section{Researcher's Positionality}

In considering the researchers' positionality, and illuminating any biases that may exist, it is important to consider the researchers' background to acknowledge the impact of assumptions and relationships with the subject matter (Giardinia \& Newman, 2011). Familiarity with the subject may allow the researchers to bring forth richer responses from the participants and to communicate in the appropriate terminology. Based on previous experiences, the researchers were compelled to undertake this research for several reasons. As a former Referee Manager at USA Rugby, Author One has faced the ongoing challenges of referee recruitment and retention, and has had the opportunity to travel globally with many referees and continues to seek a more adequate understanding of the referee's role in the sporting structure. Author Two has experience officiating youth, high school, and college basketball and has also examined officiating experi- 
ences of female officials. Author Three has officiated amateur softball and basketball contests. Results and discussion are presented together below. Representative examples of verbatim interviewee responses are included to provide a deeper understanding of the themes.

\section{Results and Discussion}

The eleven referees in this study shed light on the complexity of their role at the Olympics and the accompanying role ambiguity and role conflict. Despite the expression of positive personal experiences at the Olympics, the rugby referees seemed unable to identify and define a particular role for themselves while in Rio de Janeiro. Based on the officials' re-counting, four major sources of role ambiguity and role conflict emerged: (1) Remaining unnoticed vs. media exposure; (2) The team vs. individualistic nature of officiating; (3) Being a judge vs. being an athlete, and; (4) Amateurism vs. professionalism. The following sections consider each of the four sources of conflict that emerged from the data as illustrated by direct quotes from the participants. The quotes included herein have been deemed to be representative of responses provided by the larger sample. The researchers have also included responses that diverged from the group in order to create a holistic picture of the referee experience.

\section{Remaining Unnoticed vs. Exposure}

We saw the emergence of the first role conflict in terms of how the refer- ees highlight their opinion of success: "You want the ref to go unnoticed," says RW, "and if we go unnoticed then you're [sic] playing your part." This belief was reflective of the perceptions of many of the officials and was expanded as MP expressed,

We want to be unobtrusive and uncontroversial. There's [sic] elements where we want to be part of that Rio Olympic tournament and we want rugby to be on show, but as referees we want to play as minimal a part of that as possible...I think the less involvement we have as referees, the better. Here, as previously described by (Cuskelly, et al., 2006) we also saw the referee painted as a service provider, required for the continuation of the game, but seemingly inconsequential to the overall sporting structure. This is shown as $\mathrm{PH}$ expressed, "Officials are generally the last people that they think about when planning." BF continued,

We are not part of the Olympics, we are not striving for a gold medal. For me we are just a facilitator of the event, we need to be there and for the least people talk about us. I think it's better. If no one talks about referees, I think this is the best result we can get.

The notion that the referee should remain unnoticed in the sporting schema held true across nearly every interview and while this idea does express one role expectation of the Olympic referee, other interpretations are also valid. 
This idea was quickly called into question by the participants as they considered the need for officiating exposure. As such, these dual forces contribute to role ambiguity for the Olympic rugby officials. HP and many other referees said, "It's quite nice for them to recognize that the officials are there... so it's like the IOC had acknowledged us." While the Olympic rugby referees felt that they should remain unnoticed within the scope of the game, they also recognized that acknowledgement of the referees increased their feelings of self-worth within the larger context of the Olympics. This corresponds with the findings of Steinfield, Ellison, and Lampe (2008), showing that exposure (in their study, specifically via social media) has the potential to increase feelings of self-worth and may have a bridging effect in increasing human capital. Several referees went on to say that media coverage of the officials is extremely important to help grow officiating as significant and valued and to create recognition of referees as people and role models. LA illustrated this notion by saying,

For example, this morning I was on two different news shows, which was nice. So, although people don't [sic] necessarily think about refereeing when they think about sports, when they hear these stories, it's like a light bulb moment-and it's like oh, those people are very important and they do have a very important job.
This coverage and acknowledgement is important to humanize refereeing and make it more accessible to the general sporting population. The ambiguity lies in the referee's perception that they are to remain unnoticed within the game while simultaneously representing their country and profession in an effort to humanize/recruit new referees to the role. In rugby there are a number of referees are that are known world-wide, both for their refereeing prowess and their antics-this, however, is often of concern to other referees as they are drawing too much attention to the referee within the game. CQ addressed the dichotomy that exists between remaining unnoticed and receiving media attention and exposure:

We aren't [sic] there to get the media attention, but equally we are there for people to be aware of who we are. I think sometimes you get portrayed a little bit as a robot, whereas simple things like that footage at the start, suddenly, you've [sic] got somebody smiling down the end of a camera, it's hold on a minute, they're [sic] a little more human than we thought they were. We do have senses of humor, we do have personalities, so I think that's [sic] very important that we give that insight to the general public.

The incongruity between a referee's desire to remain unnoticed while simultaneously soliciting exposure for both 
the referee and the sporting organization created a direct role conflict for the officials. Some referees suggested that the value of exposure goes beyond hypothetical referee recruitment and may lead to appointments and additional officiating opportunities for the referee themselves. $\mathrm{BF}$ explained the impact of exposure on potential appointments,

We've [sic] gotten a lot of exposure, which builds my profile as a referee. People look at you differently, seeing that you're [sic] going to the Olympics and it's a big achievement, so basically, they see that this guy has put in a lot of work and effort to get to where he is at this stage.

BF took this further expressing,

Being a referee is all about exposure... when you start they say who is this 'muppet'? [Over time] people will say this is the guy that was in the Olympics refereeing, this is the guy that refereed the last final of the Curry Cup, this is the guy that's [sic] running touch in the World Cup. So, it's more building your profile.

On the field, referees allow the players to be the focal point of the match, yet this facilitator role clashes with the sporting structure's inherent need to use the referees as a point of recruitment and retention and the referee's own need to generate exposure and creditability. The Football Association (FA) in England, for example, created a public information campaign around respecting the referee in hopes of increasing recruitment and retention of referees. Throughout the campaign various referees were highlighted to help generate exposure and awareness of the campaign (Cleland, O'Gorman, \& Bond, 2015). While all referees interviewed in this study expressed the importance of remaining unnoticed in their sporting role, many felt that a requirement of their role was to gain exposure for both themselves and their profession. Here we may contrast the intra-role conflict arising from the incompatibility of the role expectations that the referee puts on themselves and inter-role conflict arising from the referee's expectations and those of the sporting system. While the referees sought to remain unnoticed as part of the competition structure; the larger sporting system finds there is value in varying forms of exposure. Because recruitment and retention of referees is a pervasive problem amongst nearly all sporting codes (Cuskelly \& Hoye, 2004), finding a way to create media exposure for officials might help to support referees. However, the search for media exposure seems to conflict with the referees' perceived role in the sporting structure. Thus, Olympic referee organizations might consider working with referees to better determine the appropriate level of exposure.

\section{Team vs. Individual}

Another source of role ambiguity was related to the nature of officiating as a team or individual activity. Within the sport of rugby sevens, referees explained 
that they operate as a team in two ways. First, within the context of a tournament, all rugby sevens match officials operate as a cohesive unit. When at an event, referees eat together, train together, and evaluate film together. Second, in rugby sevens a team of five on-field match officials (a referee, two assistant referees, and two in-goal judges) work together to manage the match. Each official is linked to one another via a communication system to share match information in real time. Despite the creation of these team environments, referees (like players), strive to master their craft and in doing so, strive for an opportunity to advance-seeking appointment for the best tournament matches-and to compete with the referees around them. Despite this inherent competition, RC expressed,

You're [sic] only as good as your weakest link, so if I'm [sic] in the middle and I don't [sic] get good support from the guys on the side, you're [sic] never going to make it. So, a lot of times I'm [sic] only as good as the guys [sic] on the side. In terms of the Olympic experience as a referee, "we all worked really well together, I think that's [sic] the best everyone's actually worked together. Everyone was completely focused during the tournament. And we're [sic] all trying to help each other," says PH. PJ went so far as to say that the personal competition for matches was wholly overshadowed by the team aspects of the endeavor,
We've [sic] all been working together now for at least three years... They're [sic] all my best mates, that's [sic] what I'd [sic] consider them, I guess we're [sic] family, I guess that's [sic] a better word, we're [sic] all family.

The Olympic rugby referees themselves prioritized team success over individual accomplishment, but this family environment did not develop instantly. In fact, developing such a strong team environment took significant and calculated work on behalf of the referees and their management team. They worked against many of the pre-existing notions regarding the individualism of refereeing. MP explained,

A few years back when we were kind of looking at how the team was working as a group... we've [sic] had people come almost like consultants... come in and help run sessions where we really are identifying what we want to achieve as a team, how we want to operate, what our values need to be, and being deliberate about and thinking about that.

At the Olympics, for these referees, it was made clear that acting as a team member is part of the role of the referee. The official's role goes beyond the individual's drive to acquire the best appointments and truly exists in a team sphere, where the holistic success of the team defines the daily actions of the individual. This behavior appeared to be 
extended beyond the Olympic sporting context, and into other forms of the game as well.

I think we're [sic] also moving towards a more team-based environment... we need to learn as a group and grow as a group, because you won't [sic] be around to make all of the mistakes yourself, so you've [sic] just got to be able to learn in a group environment. (RW)

While the referees all expressed their belief that officiating is a team endeavor, the perceptions of others outside of the officiating sphere still see officiating as an individualistic practice. ND explained that, "at the beginning, the first one to two years in national [sic] when I had to travel around Spain, it was hard because I was alone most of the weekend. Leave on the Saturday and come back home on Sunday night." They found that because they did not have a team to travel with they experienced officiating as an individualistic endeavor. In this case, the structure and operation of the local and regional referee organizations are at odds with the referee's desires to operate in a team environment. These structures and operators often perpetuate the individualistic role of the referee due to lack of available bodies and the requisite scheduling for a significant number of matches. CB felt similarly regarding the role in the sporting context for officials, "being alone and often being the only female anywhere, it's tough," they said. The role itself was also expressed as an individualistic one, "it just takes a lot of self-discipline to live the life of a professional athlete basically, because it's an alone job-there's [sic] no one else that checks over your shoulder all the time," said WR. This idea of being alone and working alone for other competitions and in preparation for the Olympics permeated the interviews, despite the strong ties that each referee felt to their referee team at the Olympics. LA believed that, "at the national level or the regional level it is more individual... and as you get higher there's [sic] more team." The implication being that the level of competition may impact the role of the referee. Additionally, it seems that perceptions of individual performance relating to job promotions extend to the realm of officiating which in turn has created an environment that favors the referee as an individualist rather than a team player. This idea was elucidated when LA detailed "I've [sic] had a few people, questions from people going into tournaments saying 'oh, you're [sic] going to be an assistant referee? You're [sic] not going to be in the middle.' As if being in the middle was the most important thing."

The continual alternating back and forth between role expectations as the referee moved between their local and international role responsibilities created an opportunity for increased role ambiguity. Here, inter-sender conflict-the disparity of role expectations as sent by two different organizations-is shown (Kahn et al., 1964). At the international level, team and organizational goals are stressed, as 
is the importance of teamwork; while local organizations for a variety of reasons may consider treating officiating as an individual role.

With these ambiguous roles, the external perception is one of refereeing as a solitary endeavor. At the Olympic level, referees perceived themselves to be part of a team, working together with at least four other referees during each match. They are supported in this belief by their international referee management team. According to the participants, an official is part of a unit, but is often integrated into a sporting structure that promotes officiating as an individualist endeavor. As the idea of individualism was often juxtaposed with the concept of unity, officials may have difficulty in balancing these expectations.

The findings from this study resonate with prior research (e.g., Evans, Eys, \& Bruner, 2012). The referees at the Olympic event were operating in a team-based role that may be in direct conflict with the individualist-role perception of the larger sporting context or the role they find themselves in during preparation for this event. Creating a team environment can be a positive and helpful endeavor as sport managers look to retain officials. Warner and Kellett (2011) suggested that creation of an officiating community allowed for referee socialization and enhanced one's likelihood to remain in the role. It is possible that clarifying ruby referees' roles as a member of a unit, rather than as an individual, might help to support rugby officials.
Further, deliberating between individual and team role expectations is likely to create role ambiguity and conflict, which have been shown to be correlated with turnover (Van Sell, Brief \& Aldag, 1976).

\section{Service Provider vs. Athlete}

Role ambiguity and conflict existed for the referee in regards to roles as a volunteer service provider or as an athlete. During the Olympics, all match officials were provided with the same resources at the Olympics. There was no differentiation between the "ones that kind of sit on chairs and hold up sign boards and things like that" and the officials that require more physical fitness, says CB. MP continued,

I don't [sic] know how well people would take it if they were in the more non-athletic group because they might feel like they were getting treated not as well, but the sports where there's [sic] more of a physical demand placed on you, it does make sense that it's treated slightly differently.

Many of the officials are required to have their own training camps prior to the Olympics in order to acclimatize and familiarize themselves with the team. We find that the ambiguity between the role of a service provider and athlete impacts preparation and possible successes. ND felt that this was something that needed to be changed when considering the role of the referee,

We need to be there and we're [sic] training as an athlete and we think 
as athletes. We prepare, we warm up, we do mental stuff, everything in our routine is like an athlete and people need to understand that. This is one of the problems, they don't [sic] see us as an athlete, they don't [sic] treat us as an athlete.

Within the Olympic sporting context, the referees were treated as service providers, rather than athletes. Phillips and Fairley (2014) have suggested that although referees are typically considered service providers, referees find officiating to be a valuable leisure pursuit. They also put forth that officiating should be considered a leisure pursuit in its own right, rather than being relegated to a support role that only serves a purpose for the athletes or the match. CQ believed that,

The more exposure rugby will get and rugby sevens will get and they start seeing where the officials are running with the fastest players in the world and running next to them, they'll [sic] realize that you must be fit and fast to keep up with the game. The physical demands for rugby refereeing are real.

This sentiment does not seem to align with the continual framing of referees as volunteers and service providers (Cuskelly, et al., 2006). Interestingly, participants explained the similarity between themselves and an athlete. PJ expressed the view that,

I'm [sic] an athlete mainly because of what I've [sic] had to do, and sacrifice and train to get where
I am. It just doesn't [sic] happen out of nowhere, there's [sic] a lot of time and dedication. Not just physically training, but mentally and emotionally preparing yourself for these massive events. CJ, who participated as a national team rugby player, expressed similar thoughts by saying, "It's harder at this level than when I was playing. If you're [sic] not physically prepared, then you can't [sic] mentally handle the decisions. In fact, I'm [sic] training harder than I was when I was playing." The rugby referees interviewed all considered themselves to be athletes, clearly differentiating themselves from that of a service provider. They acknowledged the significant commitment that is required to physically and mentally prepare at such a high level and to perform within high-stress, high-viewership environments and expressed that it is often the perception of others that bars them from consideration as an athlete. $\mathrm{PH}$ expressed, "They're [sic] kind of in awe. A guy in [my] office said, 'are you training for anything', and I said I'm [sic] training as an Olympic referee, and he didn't [sic] know what to say, he kind of went, 'wow, okay'."'

At the Olympics, the dichotomy still existed between the referee as service provider versus the referee as an athlete. Consistency in appropriate role designation for rugby referees may alleviate stressors, providing them with the necessary platform and framework to perform at an optimal level. Beyond this, if referees are re-framed as athletes, rath- 
er than sporting service providers, the connotation of officiating may be altered and become more supportive of rugby referees.

\section{Amateurvs. Professional}

The final source of ambiguity and conflict with regards to the referee's role is that of the amateur and the professional. Officiating was often related to volunteerism and "giving back to the game." As such, it is framed as an amateur pursuit that one pursues in their free time (Cuskelly \& Hoye, 2004). In this way, refereeing is executed as a means to support the match, rather than being addressed as a meaningful endeavor in its own right (Phillips \& Fairley, 2014). Even at the Olympic levels, many of the referees were expected to exist as professionals while being treated like amateurs. PH explained, "I don't [sic] get tournament fees or match fees. I do train six days a week, but I have to do that around a schedule that is real life. I would be a full-time ref if I could, but I can't [sic]." ND noted that they and most rugby sevens referees, even at the elite levels, "Don't [sic] have support, and I think we need to ask to the union and to the government, for the same program that players and coaches have." Even at this elite level, only two of the female Olympic sevens rugby referees had contracts with their unions. On the men's side, contracts were more frequent, but typically resulted from the referee's participation in professional 15 s competitions. With this being said, even the funded referees that come from strong rugby nations find little support. PJ stated, "We don't [sic] get any support from the Olympic committee like the athletes do, so we don't [sic] get that medical advice [or] extra grants for training." Most of the officials expressed sentiments similar to these: "I would like to be an official full time if it's going to pay the bills and ensure that I'm [sic] financially free, but at this time it isn't [sic] the case, so I have to have a second job as well." as explained by RC. Beyond the financial stresses of refereeing at elite professional level events with amateur level support, the referees also clarified that some of the support structures that have helped them to reach the Olympics were less than professional. In this regard, the responses seemed to be a bit varied. Some felt that their referee management structures were incredibly well managed, and thus those officials reflected positively on those experiences. However, such positive comments tended to stem from referees who were financially supported by their rugby union or home country and these referees tended to be from countries where there were strong professional rugby competitions. Other officials expressed dissimilar experiences, saying they lacked financial backing and also lacked the necessary behavioral and psychological mentoring from their governing body. "The management needs to... ask, "What does a professional referee need?," said BF.

A lack of financial and organizational support seemed to be the key factors that defined amateurism for referees at 
the Olympic level. While some operated as full-time employees of their country's rugby union, others maintained non-rugby careers in order to finance their officiating endeavors. The juxtaposition between amateur level support and performing in a professional environment was so stark in some cases that sporting administrators truly are expecting referees at the Olympic level to act as volunteers. Many are providing a sporting service beyond their typical "day jobs", for little to no monetary incentive. Olympic referees have to put their officiating careers on hold to ensure that they can financially support themselves. Haar, Russo, Sune, and Ollier-Malaterre (2014) found that improved work life balance is positively related to job satisfaction and overall life satisfaction, and if so, providing Olympic officials the opportunity to work as professional referees might help to eliminate managing two full-time careers in addition to other personal commitments. Referees' officiating ability is expected to be of a caliber that meets or exceeds the necessary standard of play to ensure unbridled competition for the athletes. In recognition of these needs, some rugby unions have created an officiating career development structure and funded the employment of full-time contracted referees. RW explained, I've [sic] got to be on first call for any event or any appointment that they want to send me to... and they pay me a salary whether I referee one game or I referee 30 games. I've [sic] got to run fitness testing every six weeks and I've [sic] got to pass my law exam two times a year-stuff like that [is] put in my contract.

This referee had become fully professionalized in their role within the rugby sporting structure, and as a result could be regarded as a professional in his role with the Olympics. While this was one extreme of the spectrum, many of the referees participating in the Olympics saw only a small financial reward from various rugby organizations. The expectation for professionalism went beyond on field conduct or tournament conduct. LA put forth,

It extends out into everyday living, training every day or however many times a week, and being more conscious about lifestyle choices, so I don't [sic] do anything in my normal life that could affect my position either on the national panel or the international panel. It appears that Olympic-level referees are asked be professionals, but are not generally supported as such in preparation for the Olympics. In helping to define the role of the referee, sport managers may help to clarify the referee's role as that of a professional. Framing the officiating role as one that primarily serves to "give back to the game" does not reflect the hard work and dedication that these referees exhibit day in and day out. It creates an environment where financial and organizational support are lacking, and 
often forces officials to decide between their officiating careers and their own personal or financial well-being.

Despite the ambiguity and conflict embedded in the amateur/professional divide that seems to impact the referee's role in the Olympics, we find that the referees perceived their officiating role to be of utmost importance. VL highlighted this as they explained, "If our performance is not good in the game, and then let's [sic] say it's not the right team to win the tournament; I think we'll [sic] destroy the structure of the Olympics." $\mathrm{RC}$ continued, "so basically I think it's very important for the official group to be successful for the tournament to be successful. Without a competent referee group the tournament will be flawed, which will put the game in bad repute or bad space."

\section{Conclusion}

With an important role in the Olympic sporting structure, it was noteworthy to find that the self-perceived role of the referee often lacked clarity, which created many dilemmas that the referees continually navigated. The juxtapositions of and dilemmas between the aforementioned themes of (1) remaining unnoticed, (2) team vs. individual success and development, (3) judge versus athlete designations, and (4) amateurism versus professionalism were profound. At the Olympics, ambiguity or role conflict existed at many junctures for the referee. Role ambiguity and conflict seemed to be emphasized by the referee's perceptions of their role as compared to their perceptions of expectations created by the from the larger sporting community. In the case of Rugby Sevens at the Olympics, we find the social construction of the referee as the individualist, amateur service provider in direct conflict with the referee's internal perceptions of the professional athlete and team player.

As four antecedents for role ambiguity have been uncovered at the Olympic level of officiating, the sport manager might next consider his/her role as the role sender and how conflicts and ambiguity can be created by the role sender. Further considering the source of these conflicts helps to clarify the expectations of the organization and reduce instances of role ambiguity and conflict for officials. Empowering organizations to consider strategies to help reduce role conflict for referees may help increase referee retention, which has proven to be a perennial problem.

\section{Practical Implications}

Better understanding the role of the referee provides numerous benefits to sport managers and their organizations. The ability to clarifying expectations and further define the role of the referee may help to mitigate role ambiguity and conflict, ultimately reducing turnover or burnout amongst referees. Creating a better work environment for referees not only re-frames the official's role from that of service provider to valued participant, but may also lead to increased satisfaction. The role ambiguity present- 
ed in this study suggests that sport managers should formalize agreed upon role expectations and work with officials to develop environments that facilitate their growth. Formalizing agreed expectations assists in the specification of behavioral norms, and also tends to reduce role ambiguity as employees are provided more clarity regarding employment expectations (Jackson \& Schuler, 1985). Further, this study suggests that referees should be prioritized within the sporting system and applauded for their valuable contributions to the game.

\section{Limitations and Directions for Future Research}

These findings regarding role conflict for officials are limited in their ability to be generalized as they are drawn from a specific sporting context. Participants were recruited from one Olympic sport (i.e., Rugby Sevens). Thus, it will be important to consider the perspectives from those that not only officiate team sports, but also individual sports as role is further considered. Beyond this, Rugby Sevens was included in the Olympics for the first time in 2016. As such, pre-conceptions and perceptions of role may have been impacted by the uniqueness of the event. The introduction of Rugby Sevens as an Olympic sport and experiences drawn from their participation as officials in other Rugby Sevens tournaments and in the 15-a-side version of the game may have served to set precedents upon which the officials defined their officiating roles at the Olympics. Further, the demands of athleticism and fitness in elite field sports, like Rugby Sevens, creates an officiating role that has little in common the role requirements of officials in other Olympic sports (for example, gymnastics judges). Thus, it may be beneficial for sport managers to consider the demands of each officiating role, rather than categorizing all Olympic officials collectively. In addition, role ambiguities and role conflicts should also be considered at varying levels of officiating within a sport. Anecdotally, the Olympic referees had expressed increased conflict at the local level, but perhaps this was only realized because of the comparison with the elite level.

\section{References}

Baird, L. L. (1969). A study of the role relations of graduate students. Journal of Educational Psychology. 7, 428-441. Beauchamp, M. R., Bray, S. R., Eys, M. A., \& Carron, A. V. (2003). The effect of role ambiguity on competitive state anxiety. Journal of Sport and Exercise Psychology, 25(1), 77-92.

Beauchamp, M. R., Bray, S.R., Fielding, A., Eys, M.A. (2005). A multilevel investigation of the relationship between role ambiguity and role efficacy in sport. Psychology of Sport \& Exercise, 6, 289-302.

Beehr, T. A., Walsh, J. T., \& Taber, T. D. (1976). Relationship of stress to individually and organizationally valued states: Higher order needs as a moderator. Journal of Applied Psychology, 61, 41-47. 
Berman, M. N. (2011). On interpretivism and formalism in sports officiating: From general to particular jurisprudence. Journal of the Philosophy of Sport, 38(2), 177-196.

Biddle, B. J. (1986). Recent development in role theory. Annual review of sociology, 67-92.

Braun, V., \& Clarke, V. (2006). Using thematic analysis in psychology. Qualitative Research Psychology, 3, 77-101.

Bray, S. R., Beauchamp, M. R., Eys, M. A., \& Carron, A. V. (2005). Does the need for role clarity moderate the relationship between role ambiguity and athlete satisfaction?. Journal of Applied Sport Psychology, 17(4), 306-318.

Caelli, K. (2000). The changing face of phenomenological research: Traditional and American phenomenology in nursing. Qualitative Health Research, 10(3), 366-377.

Carron, A. V. (2003, June). What I've come to believe (so far). Paper presented at the annual meeting of the North American Society for the Psychology of Sport and Physical Activity, Savannah, GA.

Carron, A. V., Hausenblas, H. A., \& Eys, M. A. (2005). Group dynamics in sport.. Morgantown, WV: Fitness Information Technology.

Cleland, J., O'Gorman, J., \& Bond, M. (2015). The English football association's respect campaign: The referees' view. International Journal of Sport Policy and Politics, 7(4), 551-563.

Cuskelly, G., \& Hoye, R. (2004). Recruitment and Retention of Sport Offi- cials. A report prepared for the Sport \& Recreation New Zealand.

Cuskelly, G., Hoye, R., \& Auld, C. (2006). Working with volunteers in sport: Theory and practice. Routledge.

Creswell, J. (2013). Qualitative inquiry and research design: Choosing among five approaches. ( $3^{\mathrm{rd}}$ ed.) Thousand Oaks, CA: Sage.

Crotty, M. (1998). The Foundations of social research: Meaning and perspective in the research process. Thousand Oaks, CA: Sage.

Dahlberg, K., Drew, N., \& Nystrom, M. (2008). Reflective lifeworld research (2nd ed.). Lund, Sweden: Studentlitteratur.

Dell, C., Gervis, M., \& Rhind, D. J. (2016). Factors influencing soccer referee's intentions to quit the game. Soccer \& Society, 17(1), 109-119.

Dorsch, K. D., \& Paskevich, D. M. (2007). Stressful experiences among six certification levels of ice hockey officials. Psychology of Sport and Exercise, 8(4), 585-593.

Evans, M. B., Eys, M. A., \& Bruner, M. W. (2012). Seeing the "we" in "me" sports: The need to consider individual sport team environments. Canadian Psychology, 53(4), 301.

Eys, M. A., Carron, A. V., Beauchamp, M. R., \& Bray, S. R. (2005). Athletes' perceptions of the sources of role ambiguity. Small Group Research, 36(4), 383-403.

Eys, M. A., Carron, A. V., Bray, S. R., \& Beauchamp, M. R. (2005). The relationship between role ambiguity and intention to return the following 
season. Journal of Applied Sport Psychology, 17(3), 255-261.

Eys, M., Carron, A., Bray, S., \& Beauchamp, M. (2003). Role ambiguity and athlete satisfaction. Journal of Sports Sciences, 21(5), 391-401.

Giardinia, M. D., \& Newman, J. I. (2011). What is this 'physical' in physical cultural

studies? Sociology of Sport Journal, 28(1), 36-63.

Glaser, B. G., \& Strauss, A. L. (1967). The discovery of grounded theory: Strategies for qualitative research. New York: Aldine de Gruyter.

Gratton, C., \& Jones, I. (2004). Research methods for sport studies. New York: Routledge.

Guba, E. G., \& Lincoln, Y. S. (1994). Competing paradigms in qualitative research. Handbook of Qualitative Research, 2, 105-117.

Haar, J. M., Russo, M., Suñe, A., \& Ollier-Malaterre, A. (2014). Outcomes of work-life balance on job satisfaction, life satisfaction and mental health: A study across seven cultures. Journal of Vocational Behavior, 85(3), 361-373.

Jackson, S. E. \& Schuler, R.S. (1985). A Meta-analysis and conceptual critique of research on role ambiguity and role conflict in work settings. Organizational Behavior and Human Decision Processes, 36, 16-78.

Kahn, R. L., Wolfe, D. M., CQ, R. P., Snoek, J. D., \& Rosenthal, R. A. (1964). Organizational stress: Studies in role conflict and ambiguity. Oxford: John Wiley and Sons.
Kellett, P., \& Shilbury, D. (2007). Umpire participation: Is abuse really the issue? Sport Management Review, 10(3), 209-229.

Kellett, P., \& Warner, S. (2011). Creating communities that lead to retention: The social worlds and communities of umpires. European Sport Management Quarterly, 11, 471- 494.

Koustelios, A., Theodorakis, N., \& Goulimaris, D. (2004). Role ambiguity, role conflict and job satisfaction among physical education teachers in Greece. International Journal of Educational Management, 18(2), 87-92.

May, K. A. (1991). Interview techniques in qualitative research: Concerns and challenges. In J. M. Morse (Ed.), Qualitative nursing research: A contemporary dialogue (Rev. ed). Thousand Oaks, CA: Sage.

Moustakas, C. (1994). Phenomenological research methods. Thousand Oaks, CA: Sage.

McGrath, J. E. (1984). Groups: Interaction and performance. Englewood Cliffs, NJ: Prentice-Hall.

Nordstrom, H., Warner, S., \& Barnes, J. C. (2016). Behind the stripes: Female football officials' experiences. International Journal of Sport Management and Marketing, 16(3-6), 259-279.

Palinkas, L. A., Horwitz, S.M., Green, C. A., Wisdom, J. P., Daun, N., \& Hoagwood, K. (2015). Purposeful sampling for qualitative data collection and mixed method implementation research. Administrative Policy Mental Health, 42(5), 533-544. 
Phillips, P., \& Fairley, S. (2014). Umpiring: A serious leisure choice. Journal of Leisure Research, 46(2), 184-202.

Polkinghorne, D. E. (1989). Phenomenological research methods. In Existential-phenomenological perspectives in psychology (pp. 41-60). Springer, Boston, MA.

Rayner, M., Webb, T., \& Webb, H. (2016). The occurrence of referee abuse in Rugby Union: Evidence and measures through an online survey. International Journal of Sport Management, Recreation and Tourism, 21 (d), 66-81.

Rainey, D. W., \& Hardy, L. (1999). Sources of stress, burnout and intention to terminate among rugby union referees. Journal of Sports Sciences, 17(10), 797-806.

Ridinger, L. L. (2015). Contributors and constraints to involvement with youth sports officiating. Journal of Amateur Sport, 1(2), 103-127.

Ridinger, L. L., Kim, K. R., Warner, S., \& Tingle, J. K. (2017). Development of the referee retention scale. Journal of Sport Management, 31(5), 514-527.

Ridinger, L. L., Warner, S., Tingle, J. K., \& Kim, K. R. (2017). Why referees stay in the game. Global Sport Business Journal, 5(3), 22-37.

Schaeperkoetter, C. C. (2017). Basketball officiating as a gendered arena: An autoethnography. Sport Management Review, 20, 128-141.

Ste-Marie, D. (2003). Expertise in sport judges and referees. In Starkes \& Ericsson (Eds.), Expert performance in sports: Advances in research on sport expertise, 169-189

Steinfield, C., Ellison, N. B., \& Lampe, C. (2008). Social capital, self-esteem, and use of online social network sites: A longitudinal analysis. Journal of Applied Developmental Psychology, 29(6), 434-445.

Stewart, D., \& Mickunas, A. (1990). Exploring phenomenology: A guide to the field and its literature. Athens, $\mathrm{OH}$ : Ohio University Press.

Taylor, A. H., Daniel, J. V., Leith, L., \& Burke, R. J. (1990). Perceived stress, psychological burnout and paths to turnover intentions among sport officials. Journal of Applied Sport Psycholo$g y, 2(1), 84-97$.

Tingle, J. K., Warner, S., \& Sartore-Baldwin, M. L. (2014). The experience of former women officials and the impact on the sporting community. Sex Roles, 71(1-2), 7-20.

Van Sell, M., Brief, A. P., \& Schuler, R. S. (1981). Role conflict and role ambiguity: Integration of the literature and directions for future research. Human Relations, 34(1), 43-71.

Vaismoradi, M., Turunen, H., \& Bondas, T. (2013). Content analysis and thematic analysis: Implications for conducting a qualitative descriptive study. Nursing \& Health Sciences, 15, 398-405. Warner, S., Tingle, J. K., \& Kellett, P. (2013). Officiating attrition: The experiences of former referees via a sport development lens. Journal of Sport Management, 27(4), 316-328. 